\title{
Discourse analysis and the study of organizations
}

\author{
DAVID GRANT and RICK IEDEMA
}

\section{Abstract}

In this paper we provide an overview of research into organizational discourse, making a tentative distinction between organizational discourse studies (emerging from organization and management theory) and organizational discourse analysis (emerging from more linguistic-oriented research). Our primary aim is to focus on organizational discourse studies in a fashion that complements, rather than replicates, previous overviews of the field. In so doing, we suggest that organizational discourse research is too complex and multivariate to be pigeonholed on the basis of academic discipline or research method. Further, abstracting the multiplicity of organizational discourse research endeavors into just two single dimensions as do Alvesson and Kärreman (2000), for example, runs the risk of losing some of this richness. We aim to provide insight into the complexity of organizational discourse and the philosophical and methodological richness that it embodies by highlighting that commentators often straddle different positions. To this end, we propose five dimensions by which to map this rich domain of research. Our concluding argument is that organizational discourse studies (ODS) and organizational discourse analysis (ODA) would do well to combine the former's normative and the latter's analytical prerogatives with attention to practitioner-situated problematics and struggles.

Keywords: organizational theory; discourse analysis; organizational research.

\section{Introduction}

In this paper we review major theoretical and analytical developments concerning the application of discourse analysis to the study of organizations. In doing so, we focus on literature that has emerged from within 
organizational and management theory, rather than on discourse analytical work carried out within the confines of linguistic, sociolinguistic, and pragmatic theory. Overviews of the latter are readily available to readers of Text from edited collections (e.g. Christie and Martin 1997; Coleman 1989a, 1989b; Firth 1995; Grimshaw and Burke 1995; Gunnarson et al. 1997; Linell and Sarangi 1998; Sarangi and Roberts 1999a; van Dijk 1997c, 1997b), state of the art papers (Coleman 1989a; Iedema and Wodak 1999; Mumby and Clair 1997; Putnam and Fairhurst 2001; Sarangi and Roberts 1999b), and books (Bargiela-Chiappini and Harris 1997; Sarangi and Slembrouck 1996; Wodak 1996). In addition, there are comprehensive studies on institutional interaction that have emerged from the domains of conversation analysis (Drew and Heritage 1992) and ethnomethodology (Boden 1994) that we also assume need little introduction here.

While the discourse analytical work that has emerged from within organization and management studies is highly varied in nature and orientation, we will collectively refer to it as 'organizational discourse studies' (ODS; Iedema 2003; Grant et al. 2004) to differentiate it from more linguistics-based approaches or 'organizational discourse analysis' (ODA). We believe that the distinction between ODS and ODA is justified on the basis of the somewhat different orientation and limited crossfertilization of these two fields. This is not to say that there are no crossovers between these domains (see, for example, Orlikowski and Yates 1994; Orlikowski et al. 1999), but rather that there is a dearth of mutual referencing. For example, neither the Handbook of Discourse Analysis (Schiffrin et al. 2003) nor the Handbook of Pragmatics (Verschueren et al. 2003) contain chapters that specifically look at the contribution of discourse analysis to the study of organizations, and both make only limited reference to organizational discourse. Moreover, while journals such as Discourse and Society, Journal of Sociolinguistics, and Journal of Pragmatics contain numerous articles that touch on organizational phenomena, these articles provide only limited references to the work of those organizational and management theorists who currently define the field of organizational discourse studies.

On the other hand, numerous special issues of management and organizational journals have appeared focusing on organizational discourse (Organization, Organization Studies, International Studies of Management and Organization, Human Relations), but few if any of the papers therein reference linguistics-based approaches to discourse analysis other than that of van Dijk (1997a) and Fairclough (1992). Similarly, a recent volume entitled Discourse and Organization (Grant et al. 1998) contains only one chapter that references work carried out in (socio)linguistics 
and pragmatics. The work of, for example, Putnam and Fairhurst (2001) represents a serious attempt to facilitate a crossover between languagebased approaches and organizational research, but studies such as this are few and far between. We argue that the dearth of such work is indicative of the fact that the concern with discourse among organizational and management theorists has tended to emerge from an interest in poststructuralist and postmodern approaches to its study rather than the approaches favored in linguistics, sociolinguistics, and pragmatics.

The present overview article comprises six sections. The present Introduction is Section 1. In Sections 2 to 4, we outline the genealogy of organization discourse studies. This involves isolating its main antecedents and explaining its current methodological multiplicity. Section 5 pursues the complex field of ODS in more detail and examines the various ways in which it contributes to the study of organizations. Here we propose five dimensions as a grid onto which to map ODS research. Finally, in Section 6 of the article, we call for a more vigorous dialogue between ODS and ODA. We suggest that researchers working under the banner(s) of ODA have much to learn from how the discourse analytical paradigm is deployed in the field of organization theory, and from what that deployment entails for discourse analysis as a form of enquiry. There is an enormous potential for ODA and ODS to act synergistically, whereby they draw on each other's attributes and complement each other in ways that enable the ODA or ODS researcher to generate productive and innovative insights into organization.

\section{Organizational discourse studies: A brief genealogy}

The origins of ODS can be traced back to a dissatisfaction with a paradigm in organization studies that emphasized the importance of organizational culture. Having come to prominence during the 1960s and 1970s, the cultural perspective on organizations sought to focus on the behavior of organizational members and how they understand each other. Up until that time, organizational theory had tended to portray organizations holistically. For example, drawing on a metaphor that had been adopted from the biological sciences, organizations were often described as 'systems' comprising formal inputs, throughputs, and outputs, and as requiring functional complementarity between subsystems (Silverman 1970). The cultural perspective helped shift analytical attention away from organizations as systems. It argued that systems views of organizations glossed over the detail and messiness of individuals' actions, not all of which could automatically be equated with the needs of the organizational 
system, its functions, or its outputs. Further, the cultural paradigm promoted a need to develop an understanding of notions such as symbol, meaning, and sign in order to carry out analysis of the meanings informing people's actions (Turner 1993). The work of those such as Putnam and her collaborators (e.g., Putnam and Pacanowsky 1983) can be located here, and can be regarded as seminal in providing an analytical framework for the study of language use in organizations.

The 1980s brought a new set of influences, predominantly to do with the growing doubt about the efficacy of existing 'structuralist' analytical approaches to explain organization, organizational culture, and (inter)action. On the strength of poststructuralist critiques of language and symbol (Bertens 1995), the culture model was in turn exposed as condoning descriptions of organizations that failed to respect the complexities of organizational life. Notably, for early culture theorists like Schein $(1983,1984)$ and Pettigrew (1979), emphasis was on the unifying rather than fragmented aspects of organizational culture. Only more recently have culture theorists tried to balance notions of cultural integration with analyses of cultural differentiation and fragmentation (Martin 2002). However, their accounts continue to take as their point of analytical departure what is shared, common, and certain, rather than that which differentiates, complicates, and defies regularity.

\section{The turn to discourse in organization theory}

In reaction to the homogenizing views of organizational language and symbol use in the study of organizational culture, organization theorists began to turn to poststructuralist theory and its concern with 'discourse' (Foucault 1972a, 1972b). In the late 1980s, 'discourse' became a theoretical device signaling a break with not just the analytical methods of the culture researchers, but also with traditional organization and management theory more generally (Burrell 1988; Cooper 1989; Cooper and Burrell 1988). Traditional theorizing was challenged on the grounds that it sought to privilege rationality by highlighting patterns, logics, and causes in a social-organizational domain where complexity and unpredictability were claimed to be the order of the day.

Given this agenda, it is not surprising that organizational theorists mounting the poststructuralist critique of existing organization and management thinking in the late 1980s set out using 'discourse' for a different purpose compared to those familiar with the term's history in (socio)linguistics and pragmatics. As readers of Text well know, in these latter domains the use of the term 'discourse' predated its popularization 
within poststructuralism by several decades (Harris 1963). Moreover, 'discourse' came to be used in (socio)linguistics and pragmatics as a term by which to describe language in social settings and served to give prominence to the formal analysis of longer (interactive) texts rather than isolated sentences (Coulthard 1977; Lemke 1995; Thibault 1991). We need to acknowledge of course that the definition of 'discourse' in linguistic approaches to discourse analysis is far from uncontested: some regard discourse to be the actualization of language as talk (Wodak 1996); others see discourse as a social formation of meanings such as 'bureaucratic discourse' (Kress and van Leeuwen 1996); again others see discourse as including both written and spoken language (Martin 1992), while still others define discourse in semiotic terms (Iedema 2003; Torfing 1999).

These differences in definition notwithstanding, ODA posits the unifying feature of discourse to lie in its manifestation as re-cognizable phenomenon (whether as talk, language, or semiosis). By contrast, the notion of discourse in ODS serves to foreground that all phenomena, whether organization, language, or identity, are inherently contingent, uncertain, unfixed - in short, 'undecidable' (Torfing 1999: 96). Accordingly, for organizational theorists like Burrell and Cooper who played a prominent role in shaping ODS, discourse constituted a worldview derived from those domains of continental philosophy that posit undecidability as being at the heart of social life (Burrell 1988; Cooper 1989; Cooper and Burrell 1988), requiring constant 'discourse work' to maintain the reality of organization and self-identity. Here then lies the prime locus of difference between ODA and ODS: the former defines discourse in the first instance in terms of empirical manifestation and regularity; the latter defines discourse in the first instance as the resource we draw on creatively and opportunistically to keep in check the existential precariousness that defines us as social-organizational beings.

Not surprisingly, Burrell's and Cooper's critiques targeted those who objectified organizational conduct as data in order to dissect it, explain it, and intervene in it. Together they created a theoretical space from within which 'organizational discourse studies' has, over the last fifteen years or so, emerged as a distinct field of enquiry (Reed 2000: 524). Interest in this field has grown to such an extent that there have recently been a number of special issues of leading management and organization journals as well as edited collections and books dedicated to the topic (Grant et al. 1998, 2001; Keenoy et al. 1997b, 2000a; Oswick et al. 1997, 2000b; Oswick et al. 2000a; Phillips and Hardy 2002). Interest in discursive approaches to the study of organization is also evident from the establishment of the biennial International Conference on Organizational Discourse, which has been running since 1994, the establishment of an 
International Centre for Research in Organizational Discourse, Strategy and Change, ${ }^{1}$ which links organizational researchers worldwide, and the recent publication of The Handbook of Organizational Discourse (Grant et al. 2004). In what follows, and notwithstanding the commonalities just outlined, we show that ODS is comprised of a field that is highly variegated, and suggest that a number of dimensions may be necessary to do justice to its richness.

\section{Organizational discourse studies: Existing typologies}

To be able to categorize the range of efforts that we can class as belonging to the field of ODS, let us begin with considering two recent descriptions of the field offered by Putnam and Fairhurst (2001) and Alvesson and Kärreman (2000).

Putnam and Fairhurst's recent chapter in The Handbook of Organizational Communication (Jablin and Putnam 2001) provides a comprehensive overview of language research done in organizational settings. The chapter is organized on the basis of different linguistic endeavors, such as sociolinguistics, pragmatics, semiotics, and critical linguistics, and it reports exhaustively on findings produced within each of these fields. In doing so, Putnam and Fairhurst's typology 'pigeonholes' people's work into either 'pragmatics' or 'sociolinguistics', presenting these as discrete endeavors. While not wanting to deny the usefulness of Putnam and Fairhurst's account, our overview below contrasts with it insofar that we believe it is important to emphasize that the work emanating from within ODS is in fact multifaceted and methodologically and philosophically complex and 'heteroglossic' (Bakhtin 1981). It is therefore not sufficient to delineate this research in terms of people's disciplinary or methodological provenance, and more appropriate to provide a way of evaluating their crossovers and fusions of methods and approaches.

For their part, Alvesson and Kärreman (2000), in a recent overview published in Human Relations, depict the field of organizational discourse research in a much more abstract way than do Putnam and Fairhurst. Instead of classifying research according to disciplinary orientation, they differentiate organizational discourse studies on two abstract dimensions. The first of these two dimensions differentiates research according to its conception of discourse and meaning. Here, Alvesson and Kärreman separate studies that accept empirical forms of discourse as adequate evidence for making claims about social and organizational phenomena, from studies that see such discourse as providing but a partial and incomplete view of such phenomena. Their second overarching dimension- 
researchers' focus of interest-differentiates research that targets local interactions ('myopic research') from 'grandiose research', which is concerned with large-scale discourses such as 'globalization discourse' or 'masculine discourse' (Alvesson and Kärreman 2000: 1130).

Alvesson and Kärreman's characterizations of ODS are suggestive, but they leave us with two key questions. First, we are left to wonder if it is possible to think of other dimensions, such as whether discourse is taken to be language or whether it can also be other forms of meaning-making, and whether discourse can be empirically studied or whether it is a rhetorical principle enabling nonempiricized arguments (Allen and Hardin 2001; Anton 2002).

The second question, which also applies to Putnam and Fairhurst's work as much as it does to Alvesson and Kärreman's, suggests that there is limited value to categorizing ODS authors in ways that appear to limit the possibility of their straddling a number of dimensions simultaneously. In our view, it is initially useful to narrow the question of organizational discourse research to matters of cognitive or focal distance (as do Alvesson and Kärreman), or to classify research into discrete disciplinarymethodological categories (as do Putnam and Fairhurst), but, having achieved that, there may be scope for presenting a somewhat more complex picture.

\section{Organizational discourse studies: An alternative overview}

We propose a multidimensional approach to characterizing the work of those whom we see as contributing to organizational discourse studies. This entails consideration of their research along the five dimensions summarized in Table 1.

Table 1. Five dimensions used to map the field of organizational discourse studies

Focus on:

\begin{tabular}{|c|c|c|}
\hline 1 & $\begin{array}{l}\text { Theory/Philosophy } \\
\text { (abstract principles of organization) }\end{array}$ & $\begin{array}{l}\text { Empirical data } \\
\text { (empirical facets of organization) }\end{array}$ \\
\hline 2 & $\begin{array}{l}\text { Monomodal discourse } \\
\text { (discourse = language) }\end{array}$ & $\begin{array}{l}\text { Multimodal discourse } \\
\text { (discourse }=\text { semiosis) }\end{array}$ \\
\hline & $\begin{array}{l}\text { 'What is' } \\
\text { (pattern analysis) }\end{array}$ & $\begin{array}{l}\text { 'What could be' } \\
\text { (marginal meanings) }\end{array}$ \\
\hline 4 & $\begin{array}{l}\text { Cognition } \\
\text { (discourse manifests cognition) }\end{array}$ & $\begin{array}{l}\text { Practice } \\
\text { (discourse manifests ways of doing and saying) }\end{array}$ \\
\hline & $\begin{array}{l}\text { Critique and emancipation } \\
\text { (discourse as a critique of power) }\end{array}$ & $\begin{array}{l}\text { Pragmatic intervention } \\
\text { (discourse as mode of intrusion) }\end{array}$ \\
\hline
\end{tabular}


These five dimensions are not meant to be exhaustive. We acknowledge that other dimensions could be proposed, or that individual dimensions could be rendered more complex than a simple continuum connecting two extremes. Nevertheless, we emphasize that our motivation for these dimensions is not to provide hard and fast categorizations of different authors' work, but rather to point to multiple divergences and commonalities over and above that which is presently understood to characterize the organizational discourse studies literature.

\subsection{Theoretical/empirical research}

Our first dimension turns on the understanding that some strands of organization discourse studies privilege theoretical discussions, while others draw quite liberally on empirical data for their arguments.

The theoretical approach to organizational discourse is oriented toward the philosophy of social organization and representation, using discourse as an abstract explanatory construct. For example, Chia, a major proponent of the theoretical approach, sees discourse as organizational principle par excellence. In his view, discourse is what underpins organization: '[d]iscourse is what constitutes our social world' (Chia 2000: 517). Discourse for him is the course or path that is created out of prediscursive chaos, reminiscent of Hjelmslev's notion of 'purport' (Hjelmslev 1961). As such, discourse is that which serves to stabilize and organize the flux of reality.

Discourse works to create some sense of stability, order and predictability and thereby produce a sustainable, functioning and livable world from what would otherwise be an amorphous, fluxing and undifferentiated reality indifferent to our causes. This it does through the material inscriptions and utterances that form the basis of language and representation. (Chia 2000: 517)

More recently, Chia (2003: 111) has noted that '[1]anguage and discourse are multitudinal and heterogeneous forms of material inscriptions or verbal utterances occurring in space-time. They act at a far more constitutive level to form social objects such as "individuals" and "organizations". Framed in these terms, discourse is not a set of meaning-makings tied to a particular site of enactment or to particular actors. Rather, it comprises sets of operations that precede actors and organizations. 'Organizational discourse ... must be understood ... in its wider ontological sense as the bringing into existence of an organized or stabilized state' (Chia 2000: 514). Drawing on the philosopher A. N. Whitehead, Chia (2003: 111112) challenges "the apparent solidity of social phenomena such as "the organization"' because he sees them deriving 'from the stabilizing effects 
of generic discursive processes rather than from the presence of independently existing concrete entities.'

While his more recent articles pay increasing attention to specific aspects of language and the historical role of writing, Chia's work can be seen as 'theory oriented'. In this respect, Chia's work resembles that of Cooper's, one of the above-mentioned initiators of the poststructuralist critique in organization studies (Cooper 1992, 1993, 1998). The primary focus of Chia's and Cooper's work is on abstract sets of relations and organizational principles, without making reference to what the linguistically trained discourse analyst would see as empirical data. In fact, they regard empirical evidence per se as no more than a rhetorical convention: it feigns realness by 'mimicking reality' (Cooper 1989).

The empirical approach, by contrast, draws on ethnographic and transcript data to make a case about the unstable nature of organization (Boje 2001; Gabriel 2000). Those researchers who adopt this approach allow for discourse to become manifest and, to a lesser extent, analyzable. Taking inspiration from Hazen's (1993) work, Rhodes (2002: 104) argues:

Organizations can thus be understood as socially constructed verbal systems in terms of stories, discourses and texts where each person who is part of the organization has a voice in the text but where some voices are louder, more articulate and more powerful than others ... Such a textual approach sees the organization as being constantly interpreted and re-interpreted by its members and others who come into contact with it.

Strictly speaking, Rhodes' work occupies an intermediate position. On the one hand, he is suspicious of simple representations and interpretations of what specific people do and say in organizations, while on the other he does make room for the representation of human experience in the form of his own voice. He achieves this by adding his personal interpretation in the right-hand margin of his more technical writings that address the discursive constitution of organization (Rhodes 2001, 2002).

Moving further toward the work of those who regard organizational data as valid means for understanding and talking about organization, we find that there are a range of types of data used. For example, there are those who draw on documentation such as memos and correspondence as empirical evidence for particular discourses (Hardy et al. 2000; Phillips and Hardy 1997), while others focus on talk at meetings as a legitimate source of organizational discourse data (Putnam and Roloff 1992).

A growing domain within organizational studies focuses on 'storytelling' and uses transcripts of stories as data. Confirming our point about ODS interest in the essential undecidability or openness of organizational life, stories are generally treated as evidence that organization encompasses 
more than formal rules and regularities. At the forefront of this storytelling research is Boje, who posits that stories are the essence of organizational reality. For Boje (1991: 111), stories are particular facets of organizational discourse and require delicate skills on the part of the storyteller:

being a player in the story-telling organization is being skilled enough to manage the person-to-person interaction to get the story-line woven into the ongoing turnby-turn dialogue using a broad class of behaviours called qualifiers, markers, and the like, that sustain story-telling across extended discourse by means of paralinguistic and kinesic cues such as head nods, postural shifts and eyebrow raises.

Further underscoring the interest in stories as the interstice between organization and disorganization (Cooper 1993), Boje is particularly concerned with what he terms 'ante-narratives' or stories that have not yet sedimented into accepted lore or practice and taken on recognizable generic features (Boje 2001).

Storytelling research also serves to frame organization as an essentially dialogical entity (Eisenberg and Goodall 1993). Its main proponents treat stories as empirical manifestations of workers' unique experiences, thereby illuminating the complexity and lived plurality of organizational life (Boje 1991, 1995, 2001; Boyce 1995, 1996; Czarniawska-Joerges 1997, 1998; Gabriel 1995, 1998; Phillips 1995). These researchers collect and transcribe both organization-centered and less formal(ized) narratives. In suggesting that storytelling research is empirically oriented we are not asserting that this work is untheoretical. On the contrary, it theorizes extensively. Our point is that, in contrast to the more theory-oriented approach of those reviewed above, storytelling research runs its arguments parallel to data collected in organizations and may display that data as illustration or evidence.

In sum, within ODS, it is possible to identify theorists like Chia and Cooper, for whom discourse represents an abstract set of structuring principles or relationships that lie beyond what people do and say. Their writings refrain from illustrating arguments with the help of discursive examples. Conversely, it is also possible to identify authors such as Boje, Gabriel, and Czarniawska, for whom the principal manifestation of organization is the stories that people tell. Their arguments tend to refer to what we may call empirical data.

\subsection{Monomodal/multimodal discourse}

A second dimension that can be used to illuminate differences and commonalities among researchers in the field of ODS concerns whether 
researchers limit their attention to language in organizations, or whether they focus on other kinds of meaning-making as well. Boje's statement above highlighted the potential significance of postural shifts and raised eyebrows, although his own work does not in fact venture into any analysis of this 'multi-modal' domain (Kress and van Leeuwen 2001). In general, most of the ODS research remains predominantly language focused and therefore monomodal (Heracleous and Barrett 2001; Heracleous and Hendry 2000). The assumption appears to be that understanding of linguistic representation and practice is adequate for accounting for and reasoning about the phenomenon of organization (Raisanen and Linde 2004).

Earlier we commented on Chia's work and its theoretical orientation. Here, we note that his writings are also increasingly concerned with language and especially writing as the basis of social organization. In Chia's (2003: 107) view, it is predominantly language-related phenomena such as '[n]ames, symbols, concepts, and categories [that] help objectify our experiences to ourselves and in so doing help make a more stable and predictable and hence liveable world.' Others are also inclined to take the view that discourse pertains to language by classifying organizational discourse as 'talk' (Hardy et al. 1998a; Marshak 1998).

This monomodal or language-centric orientation has been critiqued by Reed (2000: 528), for whom 'it is what a discourse does, rather than what it represents and how it represents it, which is the central explanatory issue'. Reed's impatience with representation derives from its inability to come to terms with the 'mate-real' effect of how people use representation for material ends. For this reason, he 'shifts the direction of discourse analysis away from a single-stranded focus on the symbolic representation and communication of "constructed worlds" towards a much broader concern within the political economy of discursive formation and its long-term institutional effects' (Reed 2000: 528).

Reed's critique essentially targets the way that (Foucaultian) discourse analysis ignores nonlinguistic effects: 'Foucauldian discourse analysis ... [denies] itself the very opportunity and resources to understand and explain the generative properties that make social practices and forms ... what they are and equip them to do what they do' (Reed 1998: 210). While inappropriately dismissive of Foucault (who was crucially concerned with the material implications of the Panopticon and other spatial, technological, and bodily materialities and inscriptions), the value of Reed's work is that it highlights the problem that arises in those areas of organizational discourse studies where the linguistic dimension of discourse is promoted to the exclusion of other aspects of meaningmaking. 
That said, critical reading of the organizational discourse literature reveals it harbors definitional tensions and ambiguities. Is discourse talk? Is it language? Is it meaning-making in general or 'semiosis'? For instance, Keenoy, Oswick, and Grant's (1997a: 148) introduction to a special issue of Organization on organizational discourse research cites predominantly language-based research, suggesting that discourse encompasses the study of 'stories and novels, text, narrative, metaphor conversation and language games'. Yet, in a subsequent article (Keenoy et al. 2000b: 542544), these same authors go well beyond this linguistic delineation of discourse when they praise an account of organization (Robb 1998) which is clearly multimodal with references to 'the food they [Robb's organizational members] ate, $\ldots$ the building projects they financed, ... their homes, habits, values, procedures, policies, business strategies ...'

One scholar within organization theory who is explicit about his multimodal view of meaning-making is Gagliardi, even though his work is not strictly 'discourse' based. Gagliardi's research focuses on organizational artifacts (Gagliardi 1990; Gumbrecht and Pfeiffer 1994) in so far that they 'are pathways of action' (Gagliardi 1990, p.16). Gagliardi's work reflects Bourdieu's views on the structuring influence of social architecture and geography (Bourdieu 1994). Thus, he believes that:

the physical setting influences the behaviour of actors, since the first thing it does is to limit and structure their sensory experience. A specific setting allows us to do some things and not others - i.e. it sets us physical bounds in a strict sense - and it gives rise to certain sensation and not others. (Gagliardi 1990: 18)

Another strand of research that gives prominence to the empirical study of multimodal practices in organizations is actor network theory or ANT. ANT has set great store by the ways in which people-artifact relationships and transformations impact on organization and social organization more broadly. ${ }^{2} \mathrm{We}$ will address ANT in more detail when addressing the dimension of cognitivist and 'distributed knowledge' approaches to organizational discourse research below (Section 5.4).

\subsection{Discourse as pattern/change}

A third dimension that can be used to differentiate ODS scholars and locate their commonalities considers whether researchers aim to unearth patterns of discourse in organizational settings, or whether they are concerned to create a space for people to go beyond patterned and predictable conduct, thereby facilitating organizational change and innovation.

Those ODS researchers who are interested in discourse as patterned conduct have potentially much in common of course with people working 
as organizational discourse analysts (ODA). This is recognized in Putnam and Fairhurst's (2001) and Woodilla's (1998) mappings of the field of organizational discourse research, both of which highlight those kinds of organizational discourse research whose disciplinary and methodological orientation draws on sociolinguistics, conversational analysis, pragmatics, and related fields.

The work in question here pursues rather formal analyses of the different facets of organization, and therefore sits somewhat uneasily with ODS' broader brief (outlined above), which seeks to privilege undecidability. We will briefly expand on this body of literature, however, to highlight its intermediate position between ODS and ODA. Here, three levels of analytical concern can be identified: the micro, meso, and macro. These equate to the three main units of analysis in mainstream organization theory: the individual, the group, and the organization. At the microlevel, researchers have used the notion of discourse to study the individual insofar as this can offer insights into the attitudes, affiliations, orientations, motives, and values of a given organizational stakeholder (Grant 1999; Oswick and Montgomery 1999; Salzer-Morling 1998). At the meso-level, we find people doing research into group dynamics, meetings, negotiations, and conflict (Cobb and Rifkin 1991; Hamilton 1997; Mauws 2000; Putnam and Roloff 1992; Woodilla 1998), some using 'genre' as explanatory construct (Orlikowski and Yates 1994; Orlikowski et al. 1999). The macrostrand targets 'large' discourse formations, such as the discourse of organizational change (Dunford and Palmer 1996) or the new public management and managerialism (Anderson-Gough et al. 2000; Ford and Ford 1995; Maguire 2004; Phillips and Hardy 1997).

On the other hand, ODS researchers have started to challenge the conventional perspectives that underpin the above-mentioned segregation into research on individuals, teams, and whole organizations. In what Keenoy, Oswick, and Grant (1997a: 147) have described as a 'meltdown of taken for granted meanings', traditional bureaucratic approaches to what makes up organization have given way to postmodern perspectives that favor seeing the organization as comprised of paradoxical, fluid, and contradictory processes and practices. These latter perspectives are believed to do more justice to the incoherence and inconsistency underlying what organizations and their managers do as they attempt to cope with the escalating demands of globalization and the increasing unpredictability of 'the market'. The focus on fluidity and uncertainty in order to describe, theorize, and interpret what is taken to be organizational reality has allowed these researchers to shirk claims about what commonly occurs in favor of claims about complexity and undecidability. This leads us to the second main strand of research under scrutiny here. 
In contrast to the concern with discourse patterns, then, a very prominent and influential strand of research within ODS focuses on that which appears unpatterned: the absence of regularity; the singular, peculiar, and marginal, and the space of potential change and innovation. For example, researchers focus on graffiti, conflict, emotion, antimanagerial sentiments, and the like. The aim of this research is not to understand what kinds of meanings and discourses currently characterize formal organization, but rather to isolate and learn from new and hitherto marginal(ized) kinds of meanings. Researchers adopting this approach seek to reinvigorate Cooper and Burrell's reservations about the legitimacy of methodical 'discourse analysis', and reassert the importance of 'discourse' as a means for illuminating play, contradiction, and dialogism (Boje 2001; Keenoy et al. 1997a), or 'heteroglossia' (Bakhtin 1981; Rhodes 2001, 2002). The research deliberately refrains from generalizing about organizational practices and discourses to deny these legitimacy. Its emphasis is not so much on engendering insight on the part of organizational members into the conventional nature of their own practices, as on encouraging and enabling practices within which employees are able to explore new possibilities, new relationships, new selves, and new meanings.

At the heart of this research enterprise is the normative view that '[o]ntologically, no story has precedence over another [and] a hierarchical ordering of privileged and marginalized discourses is not evident' (Keenoy et al. 1997a: 150). Referred to as 'monological' in orientation (Grant et al. 1998: 7; Keenoy et al. 1997a: 149), formal analytical descriptions are taken to gloss over the plurality of views and interpretations that is elided in favor of highlighting analytical regularity. From a monological viewpoint, the organization is read 'as one story, usually viewed from the perspective of the dominant group' (Boje 1995: 1029; Keenoy et al. 1997a: 149). Instead, the preferred stance on organizational discourse is a 'dialogical' one that:

recognizes and legitimises the multiple independent voices and potentially autonomous discourses which contribute to the plurivocal meaning and interpretations $\ldots$ of any given organizational reality. (Keenoy et al. 1997a: 149)

Already mentioned above for his contribution to empirical discourse research, Boje $(1995,2001)$ is also a prominent proponent of this 'dialogical' approach to the study of organizational discourse. As flagged above, Boje places great emphasis on working with what he calls 'antenarratives' that have not yet had the chance to crystallize out into conventionalized genres or stories, and whose destabilizing, innovative, and creative potential therefore remains high.

Much like Boje, Gabriel (1995) puts the spotlight on those aspects of organization that exceed the sphere of management and control. 
Gabriel's interests lie in jokes, nicknames, and graffiti. He suggests that, far from being marginal to organizational reality, these 'unmanaged' and unsupervised phenomena are central to enabling employees to formulate alternative kinds of subjectivity. This enables them to escape or 'supplement fictions of the self created by management and control' (Gabriel 1995: 493). Similarly, Czarniawska-Joerges (1997: 62) seeks to demonstrate how organizational narratives are used to purvey 'an attitude of outsidedness, which offers different grounds for communication ... It aims at understanding not by identification ("they are like us") but by the recognition of differences- "we are different from them, and they are different from us; by exploring these differences we will understand ourselves better"' (her italics).

What these latter studies have in common is that they are not interested in identifying what characterizes organization, organizational discourse, or organizational practice. Instead, they seek to give voice to kinds of discourse that are marginal and that, thanks to their marginal status, afford new ways of seeing what the organization is or does, or new ways of being for organizational members. For commentators like Boje, Gabriel, and Czarniawska, these new points of view arise from employees being able to pursue meanings and discourses that exceed conventional and restricted ways of talking. These meanings and discourses escape the reaches of management and control and therewith established forms of identification and organization.

Others who do not identify themselves with the empirical objectives of the storytelling research just cited, but who certainly share its desire for change and innovation, are authors like Burrell (1988, 1997, 2001), Cooper $(1989,1992,1993,1998,2001)$, Chia (1998, 2000, 2003), and Rhodes (2001, 2002). As noted earlier, Burrell and Cooper have become increasingly critical of traditional, rational, and analytical approaches to seeking to understand organization. Both these authors, especially in their recent work, have produced challenging ruminations to try to overhaul what they see as a technicalized organization studies (Burrell 1997, 2001; Cooper 1998, 2001). Burrell's (1997) work, for example, has provided an at times emotionally disturbing account, engendering a highly unconventional view of the social, political, and economic processes that underpin organizational phenomena.

\subsection{Cognition/practice views of discourse}

The cognition-practice dimension of ODS contrasts discourse as the effect of thinking to discourse as a manifestation of social practice. A good number of those working under the umbrella of organizational 
discourse studies rely on the former, or what some refer to as a 'cognitivist' view of discourse (Still and Costall 1991); that is, the view that cognition is both prediscursive and determining of discourse (Reddy 1979). Here, the view is that 'mental models influence organizational experiences' (Putnam and Fairhurst 2001) or that cognition dictates the shape of discourse and meaning. In contrast to this 'cognitivist' stance, there is the view that discourse, including cognition, emotion, and social organization, needs to be seen in the first instance as constituted socially and dialogically (Gergen 2000, 2001; Shotter and Cunliffe 2003; Shotter and Gergen 1989). This latter work ties in with a growing body of action research that uses conversation to achieve organizational change (Ford and Ford 1995; Ford 1999; Ford and Ford 2003; Shaw 2002).

This privileging of human cognition over social practice is not uncommon in the ODS literature. For example, earlier we commented on the two dimensions used by Alvesson and Kärreman (2000) to map the field of ODS. On further scrutiny, these authors can be seen to use the second of their dimensions to promote the view that the source and logic of discourse is not in the first instance social practice (Schatzki 2002), but the cognizing subject. In doing so, they posit that cognition should be seen as primary and prediscursive, and that discourse should be seen as its incomplete and approximate manifestation. This perspective is shared by Heracleous and Barrett (2001: 758):

In the domain of discourse, we have approached deep structures as persistent features of discourse that transcend individual texts, speakers, authors, situational contexts, and communicative actions and pervade bodies of communicative action as a whole and over the long term.... these structural features are rules and resources that have no 'real' existence other than as interpretive schemes... Interpretive schemes can be seen as psychological frames ... that provide the cognitive structuring necessary for constructing workable cognitive representations of the world.

Other studies by organization theorists that could be said to have a cognitivist orientation include Gabriel's (1999) examination of the insights psychoanalysis can offer to the study of organizations and organizational behavior, Mangham's (1998) observations about the discursive features of emotion in organization, and Cohen and Mallon's (2001) social cognitive study of how workers make sense of their careers. An important exception here is Weick's research, where the analysis of sense-making in organizations centers on social-interactive definitions of 'mind' (Weick and Roberts 1993).

In contrast to this overarching concern with cognitive schemes or frames, there is a small body of work that posits social practice as 
providing the origin and logic of discourse. Already encountered above, Gagliardi (1990) is an organization theorist for whom culture, organizational knowledge, and discourse are not entirely contingent upon and shaped by cognitive schema or frames. Gagliardi (1990: 13) goes so far as to suggest that our obsession with cognition (to the exclusion of material social practice) is at the root of what he sees as 'our incapacity to give exhaustive explanation' to organizational phenomena. Moreover:

the emphasis on mental processes and cognition is probably at the origin of our incapacity to give exhaustive explanation to such [...] fundamental organizational processes as control, persistence, [and] change.... (Gagliardi 1990: 13)

In direct contrast to those views of meaning and discourse that locate their source, cause, and form in the mind, Gagliardi favors a practicecentered, material, and dispersed view of meaning-making (Gee 1992; Lave and Wenger 1990).

Wenger, an organization theorist whose work focuses on 'communities of practice', sees mental schemes as integral to situated practice but not as determining of practice: 'this perspective does not imply a fundamental distinction between interpreting and acting, doing and thinking, or understanding and responding. All are part of the ongoing process of negotiating meaning'. In contrast to Alvesson and Kärreman, Wenger locates the logic of organization in people's shared meaning-making practices. More precisely, for Wenger (1998: 55) it is the tension between human interaction on the one hand, and the tools, technologies, language forms, and artifacts that humans use in interaction on the other hand, that produces meaning, or where 'the negotiation of meaning takes place'.

Also building on a practice-centered view of organization is the work of those in the area of actor network theory, or ANT for short (Callon 1986; Fox 2000; Latour 1986; Law 1994, 1999; Law and Bijker 1992). Law (1994: 108), in his rather idiosyncratic writing style, defines ANT as follows:

Actor-network theory is another recursive sociology of process. In some ways it is remarkably like symbolic interaction. But it is symbolic interaction with an added dash of Machiavellian political theory, a portion of (suitably diluted) discourse analysis, and a commitment to the project of understanding the material character of the networks of the social. ${ }^{3}$

Sharing this stance with authors such as Gagliardi and Wenger, ANT does not privilege individuals as the sole source of meaning and discourse, since it sees all sorts of different phenomena-both human and nonhuman - as potentially contributing to the shaping of social and organizational life. More specifically, ANT's primary focus is on how 
meanings get translated from one form into another (Iedema 2001). As Law and Bijker (1992: 294) put it: 'much of the time people try to devise arrangements that will outlast their immediate attention. That is, they try to find ways of ensuring that things will stay in one place once those who initiated them have gone away and started to do something else.'

A particularly prominent strand of research within ANT has been the tracing of the formation of such 'black-boxing' arrangements that will 'outlast people's immediate attention'. Thus, ANT has described the sociotechnical processes or 'translations' that affected the production of the fluorescent high-intensity lamp, the construction of the Paris underground, the politics around the introduction of clinical budgeting, but also the genealogy of scientific findings and social knowledges (see the papers in Bijker and Law 1992). The processes of translation that these phenomena undergo typically move from ephemeral manifestations toward durable manifestations, or from 'it's just a story', via 'it's just a laboratory artifact' to 'it's probably a fact' (Latour 1992: 62). Equally, translations can move from people to nonpeople or machines (and back). It is these translation processes and dynamics that are central for ANT, insofar as they exploit language, people, discourses, organization, and meaning. ${ }^{4}$

The distinctions between humans and non-humans, embodied or disembodied skills, impersonation or 'machination', are less interesting than the complete chain along which competencies and actions are distributed (Latour 1990: 243).

For Law (1994: 95), discourse provides a means for pursuing a research program that focuses on the processual, relational, and material dimensions of organization. Accordingly, he describes his approach toward discourse research in the following terms:

first, we should treat it [discourse] as a set of patterns that might be imputed to the networks of the social; second, we should look for discourses in the plural, not discourse in the singular; third, we should treat discourses as ordering attempts, not orders; fourth, we should explore how they are performed, embodied and told in different materials; and fifth, we should consider the ways in which they interact, change, or indeed face extinction. (Law 1994: 95)

No doubt due to his materialist, multimodal view of discourse, Law's work is also highly practice centered, analytical, and empirical. What counts for Law are the manifest outcomes of practices and their material appearance. These practices chain human actors and nonhuman actors together into a complex weave of discursive translations. Not surprisingly, ANT's view is that cognition is but one facet of the translations that rematerialize discourses across social times and spaces, and of the different knowledges that these translations make available. 


\subsection{Discourse research as emancipatory critique/pragmatic analytics}

Our fifth and last dimension differentiates critical research from pragmatic research in ODS. In the case of the former, the research fits into a critical-theoretical mould insofar as it is concerned to critique organizational forms of power and dominance. In the field of organization studies, Reed's work epitomizes this perspective. Indeed, Reed's work is critical in a double sense: he critiques the power relations in which organizations are embedded, and he critiques those domains of social science (i.e., discourse analysis) that fail to alert us to these sociomaterial inequities (Reed 1997, 1998, 2000).

A host of other authors have also sought to achieve a greater understanding of how power relations and associated knowledges and identities affect the processes of organizing and the conduct of organizational members, using descriptive methods to critique the status quo (Alvesson 1994, 1996; Hardy et al. 2000; Hardy et al. 1998b; Iedema et al. 2004a; Knights and Morgan 1991; Knights and Willmott 1989; Lawrence et al. 1999; Mumby 1998; Mumby and Stohl 1991; Phillips and Hardy 1997). Many of these have rallied around what is now known as the field of 'critical management studies'.

Some critical commentators favor plurivocality and heteroglossia (Bakhtin 1981) as ways of challenging established, monological, and dominant versions of organizational reality. Here we can mention (again) Boje (1991, 1995, 2001), Czarniawska-Joerges (1997, 1998), Gabriel (1995, 2000), and Rhodes $(2001,2002)$. Each of these authors seeks to create a space for the unheard, and unsettle the dominant discourses that define, constrain, and impose closure on organization. For example, Gabriel (2000: 18) proposes that '[s]tories re-enchant the disenchanted' while for Boje (2001: 4) 'ante-narrative' is what gives a view on those aspects of organization that are in a 'state of coming-to-be, still in flux'. Similarly, Czarniawska-Joerges (1997) believes that organizational members often use stories to demonstrate how they differ from those around them, and more specifically from what the organization requires them to be, thereby bolstering their sense of individuality. Rhodes (2002: 108) charges 'conventional genres of writing organization' with acting 'to suppress the heteroglossia by limiting alternative portrayals' and calls for approaches that serve to emancipate those who are not heard. For each of these commentators, then, the pursuit of new meaning is closely matched with the original critical-theoretical aim of challenging established relationships of power.

In contrast to those who have adopted the critical-theoretical stance, there are those who belong rather in what we may call the "pragmatic- 
interventionist' camp. Here the concern is to use discourse as a means to enhancing performance, improving the effectiveness of management, or creating greater allegiance and efficiency among employees. Some of this work has been touched on above, notably when we discussed research whose analytical purchase of situated interaction contributes to a better understanding of intraorganizational relationships and processes. Leaving aside the communication research pioneered and reviewed by Putnam and Fairhurst (2001), ${ }^{5}$ we might flag work that has started to fuse Ford and Ford's (1995) 'story-telling as organizational change', Wenger's (1998) 'community of practice', and Shotter's (1991) notion of the 'dialogical constitution of self' in order to achieve pragmatic outcomes for organizational change projects (Shaw 2002; Taylor and Van Every 2000).

We should note that the above differentiation of the critical and pragmatic approaches to discourse analysis is nevertheless a fragile one. This is because the concern with plurivocality in organization studies is often closely aligned with the search for organizational innovation and change in the face of external challenges. Boje's (1994) work in particular operates at the interstice between liberating repressed voices on the one hand, and enhancing the organization's capacity for learning on the other hand. As such, it straddles the critical-theoretical as well as the pragmaticanalytic camps and therefore exemplifies an intriguing confluence of postmodern, critical, and pragmatic change perspectives.

\section{Discussion and conclusions}

Our point of departure in this article was to distinguish organizational discourse analysis (ODA) from organizational discourse studies (ODS). Our reasoning in favor of this distinction centered on three arguments. First, we recognize that for ODS researchers the notion of discourse does not entrain a set of technical-analytical procedures, but provides a way to focus on and foreground the contingency and uncertainty of social and organizational phenomena. Rather than 'studying discourse' in the sense of describing the regularities of a well-defined and existing (empirical) object, ODS researchers tend to see discourse as the work that people do in the face of undecidability, and use it as a device with which to bypass ordinary organizational phenomena and instead focus on the unusual (Boje's 'antenarratives'), 'what is not' (Chia's and Cooper's 'illusion of simple location'), and the marginalized (Gabriel's graffiti). Second, we pointed to the relative dearth of mutual referencing across ODA and ODS literatures, adding to the impression that they are discrete research endeavors. Third, we noted the complaint on the part of prominent 
commentators in the field of ODS that formal analysis of organizational discourse phenomena produces merely 'monological' accounts. In their view, ODA, unlike much of the ODS research, fails to come to grips with the 'dialogical' and 'heteroglossic' complexity of discourse, or the undecidability of social and organizational life.

Emphasizing that ours is but one among a number of ways in which the task set here can be approached, we proceeded to locate the work done in organizational discourse studies along five dimensions: theoretical/empirical; monomodal/multimodal; regularity/change; cognition/practice centered; and critical/interventionist. In using this approach, we hope to have highlighted both divergences and commonalities, to have demonstrated that some authors straddle multiple dimensions, and to have illustrated how some have moved from one end of a continuum to another during their career.

Notwithstanding the distinction that we have suggested between analytical and normative approaches toward organizational discourse, we believe that it is possible to mediate between the formalizing and technical gaze of ODA and the humanizing, philosophical, and change-oriented concerns of ODS. There is an emerging body of research that we can point to that straddles these orientations and that is able to effect change through paying detailed attention to situated practice (Bloor 1997). First of all, we can point to the work of Engeström and his colleagues who have been able to combine analytical attention to situational practices and discourses with practitioner-centered ways of producing new ways of doing and saying (Engeström 2000). Their most recent project has centered on overcoming the divide that characterizes the relationship among general practitioners (who service patients in the community), specialist practitioners (who work in hospitals), and patients (who travel across sites and between clinical practitioners). This work is interventionist insofar as it targets recurrent problems and devises practical alternatives: insufficient or no communication between GPs and hospital specialists; noninvolvement of patients in making decisions about their care or a lack of care planning. Their latest project instituted a care-planning practice such that not merely those who make decisions but also other professionals (nurses, allied health, alternative medical specialists) are informed of the patient's history as well as about their care plan. Another example of research that targets the change potential of organizational practices is found in the work of Roberts and Sarangi (1999). Here the analysis of talk at oral examinations at the Royal College of General Practitioners (RCGP) in the UK served to inform the RCGP examination body about the gatekeeping effects of the oral exam, and ended up producing what Sarangi and Roberts (1999b) term a hybrid discourse that straddled 
discourse-analytical and practitioners' worlds (Sarangi and Roberts 1999b). For their part, Iedema and colleagues have engaged hospital staffs in narrative projects to enable them to move toward multidisciplinary ways of documenting and organizing their services (Iedema et al. 2005; Iedema et al. 2004b). Finally, Hardy and her colleagues have recently produced a swathe of research designed to change practitioner thinking and practice about interorganizational collaborations. Their work provides detailed analyses of the situated practices and discourses that practitioners employ in order to formulate the collective identities that underpin these collaborations (Hardy et al. 2005; Hardy et al. 2003; Lawrence et al. 2002; Maguire et al. 2001; Phillips et al. 2000). In doing so, it enables practitioners to appreciate the processes by which such collective identities come to fruition and to identify the circumstances in which they are likely to succeed or founder.

There is an important lesson to be drawn from this emerging body of hybrid research. On the one hand, we conclude from it that analytical approaches would do well to tie their analytical principles to the concerns and struggles of actors in situ. On the other hand, the alternative voices that ODS privileges through its stories and ante-narratives need to be refracted through the socio-organizational contexts and aspirations that constrain and enable those voices. Overall, organizational discourse research should make neither analytical reasoning nor normative exhortation its raison d'etre. Instead, and in line with calls to refocus on in situ work, rather than on the literary, textual, or philosophical underpinnings of discourse, stories, or other symbolic data (Barley and Kunda 2001; Blackler 1995), it should seek to anchor itself to the real-life problematics and situated outcomes that characterize organizational members' everyday existence. The onus is on both ODA and ODS therefore to study discourse in organizations in a way that neither cuts loose from situated problematics, nor naturalizes existing organizational relationships and practices, but instead gives due place to the ethical, moral, and practical dilemmas that affect organizational actors in their work and communications with other stakeholders.

\section{Notes}

1. The International Centre for Research in Organizational Discourse, Strategy and Change comprises seven institutional partners: King's College, London, UK; The Judge Institute of Management, University of Cambridge UK; The University of Leicester, UK; Lund University, Sweden; McGill University, Canada; Texas A\&M University, USA; and the Universities of Sydney and Melbourne, Australia. It provides a critical 
mass of expertise in organizational discourse and offers an innovative approach to the study of strategy and change in organizations.

2. Artifacts are also prominent in a form of enquiry into organizational practices called 'workplace studies'. An off-shoot of ethnomethodological and conversation analytical kinds of enquiry rather than strictly discourse research, workplace studies see both spaces and technologies as integral parts of the practices that people co-enact.

3. Law goes on to elaborate on his multimodal view of discourse: 'Foucauldian discourse analysis, reinterpreted in the way that I am proposing, tells us to be bold. It says, in effect, that there are large-scale patterns which reach through and are performed in the networks of the social. [These] modes of ordering may characterize and generate different materials - agents, devices, texts, social relations, architectures and all the rest' (Law 1994: 108-110).

4. ANT has recently received bad press due to the way it conceptualizes socioorganizational life as a 'flatland' where any distinction between what is human and non-human disappears into the vortex of chains of translations. ANT does not recognize different or separate social or organizational 'moments' (Harvey 1996: 78), because it sees moments like power, beliefs, values, desires, rituals, social relations, and practices as essentially co-extensive, interdependent, and interwoven in socio-organizational processes. If this is seen to produce a 'flatland', then that may be because we continue to think in essences and not in terms of relations and processes (Latour 1988; Torfing 1999).

5. For example, discourse research has enabled commentators such as Putnam and Roloff (1992) to outline the strategies of effective mediators and the dynamics of problematic negotiation.

\section{References}

Allen, D. and Hardin, P. (2001). Discourse analysis and the epidemiology of meaning. Nursing Philosophy 2 (2): 163-176.

Alvesson, M. (1994). Talking in organisations: Managing identity and impressions in an advertising agency. Organization Studies 15 (4): 535-563.

- (1996). Communication, Power and Organization. Berlin/New York: Walter de Gruyter.

Alvesson, M. and Kärreman, D. (2000). Varieties of discourse: On the study of organizations through discourse analysis. Human Relations 53 (9): 1125-1149.

Anderson-Gough, F., Grey, C., and Robson, K. (2000). In the name of the client: The service ethic in two professional service firms. Human Relations 53 (9): 1151-1174.

Anton, C. (2002). Discourse as care: A phenomenological consideration of spatiality and temporality. Human Studies 25 (2): 185-205.

Bakhtin, M. M. (1981). The Dialogic Imagination. Austin: University of Texas Press.

Bargiela-Chiappini, F. and Harris, S. (1997). The Discourse of Corporate Meetings. Amsterdam: Benjamins.

Barley, S. R. and Kunda, G. (2001). Bringing work back in. Organization Science 12 (1): 7695.

Bertens, H. (1995). The Idea of the Postmodern: A History. London: Routledge.

Bijker, W. E. and Law, J. (1992). Shaping technology/Building Society. Cambridge, MA: The MIT Press.

Blackler, F. (1995). Knowledge, knowledge work and organizations: An overview and interpretation. Organization Studies 16 (6): 1021-1046. 
Bloor, M. (1997). Addressing social problems through qualitative research. In Qualitative Research: Theory, Method, Practice, D. Silverman (ed.), 221-238. London: Sage.

Boden, D. (1994). The Business of Talk: Organizations in Action. London/Cambridge, MA: Polity Press.

Boje, D. M. (1991). The story-telling organization: A study of story performance in an office-supply firm. Administrative Science Quarterly 36 (1): 106-126.

- (1994). Organizational story-telling: The struggles of pre-modern, modern and postmodern organizational learning discourses. Management Learning 25 (3): 433-461.

- (1995). Stories of the story-telling organization: A post-modern analysis of Disney as Tamara-land. Academy of Management Journal 38 (4): 997-1035.

-(2001). Narrative Methods for Organizational and Communication Research. London: Sage.

Bourdieu, P. (1994). Rethinking the state: Genesis and the structure of the bureaucratic field. Sociological Theory 12 (1): 1-18.

Boyce, M. E. (1995). Collective centring and collective sense-making in the stories and storytelling of one organization. Organization Studies 16 (1): 107-137.

-(1996). Organisational story and storytelling: A critical review. Journal of Organisational Change Management 9 (5): 5-26.

Burrell, G. (1988). Modernism, post modernism and organizational analysis 2: The contribution of Michel Foucault. Organization Studies 9 (2): 221-235.

-(1997). Pandemonium: Towards a Retro-Organisation Theory. London: Sage.

- (2001). Ephemera: Critical dialogues on organization. Ephemera 1 (1): 11-29.

Callon, M. (1986). Some elements of a sociology of translation: Domestication of the scallops and the fishermen of St Brienne Bay. In Power, Action and Belief: A New Sociology of Knowledge? Sociological Review Monograph, J. Law (ed.), 196-229. Keele: Methuen.

Chia, R. (1998). Introduction: Exploring the expanded realm of technology, organization and modernity. In Organized Worlds: Explorations in Technology and Organization with Robert Cooper, R. Chia (ed.), 1-19. London: Routledge.

- (2000). Discourse analysis as organizational analysis. Organization 7 (3): 513-518.

- (2003). Ontology: Organization as 'world making'. In Debating Organization: Pointcounter-point in Organization Studies, R. Westwood and S. Clegg (eds.), 98-113. Oxford: Blackwell.

Christie, F. and Martin, J. R. (1997). Genres and Institutions: Social Processes in the Workplace and School. London: Cassell.

Cobb, S. and Rifkin, J. (1991). Neutrality as a discursive practice: The construction and transformation of narratives in community medication. Studies in Law, Politics, and Society 11: 69-91.

Cohen, L. and Mallon, M. (2001). My brilliant career? Using stories as a methodological tool in careers research. International Studies of Management and Organization 31 (3): $48-67$.

Coleman, H. (1989a). The present and the future of work. In Working With Language: A Multidisciplinary Consideration of Language Use in Work Contexts, H. Coleman (ed.), 109-128. Berlin/New York: Mouton de Gruyter.

-(1989b). Working with Language: A Multidisciplinary Consideration of Language Use in Work Contexts. Berlin/New York: Mouton de Gruyter.

Cooper, R. (1989). Modernism, post modernism and organizational analysis 3: The contribution of Jacques Derrida. Organization Studies 10 (4): 479-502.

- (1992). Formal organization as representation: Remote control, displacement and abbreviation. In Rethinking Organization: New Directions in Organization Theory and Analysis, M. Reed and M. Hughes (eds.), 254-272. London: Sage. 
-(1993). Organization/disorganization. In The Theory and Philosophy of Organizations: Critical Issues and New Perspectives, J. Hassard and D. Pym (eds.), 167-197. London: Routledge.

-(1998). Assemblage notes. In Organized Worlds: Explorations in Technology and Organization with Robert Cooper, R. Chia (ed.), 108-130. London: Routledge.

- (2001). Un-timely meditations: Questing thought. Ephemera 1 (4): 321-347.

Cooper, R. and Burrell, G. (1988). Modernism, postmodernism and organizational analysis: An introduction. Organization Studies 9 (1): 91-112.

Coulthard, M. (1977). Introduction to Discourse Analysis. London: Longman.

Czarniawska-Joerges, B. (1997). Narrating the Organization: Dramas of Institutional Identity. Chicago: University of Chicago Press.

-(1998). A Narrative Approach to Organization Studies. Newbury Park, CA: Sage.

Drew, P. and Heritage, J. (1992). Analysing talk at work: An introduction. In Talk at Work: Interaction in Institutional Settings, P. Drew and J. Heritage (eds.), 3-65. Cambridge: Cambridge University Press.

Dunford, R. and Palmer, I. (1996). Metaphors in popular management discourse: The case of corporate restructuring. In Metaphor and Organization, D. Grant and C. Oswick (eds.), 95-109. London: Sage.

Eisenberg, E. M. and Goodall, H. L. (1993). Organizational Communication: Balancing Creativity and Constraint. New York: St. Martin's Press.

Engestrom, Y. (2000). From individual action to collective activity and back: Developmental work research as an interventionist methodology. In Workplace Studies: Recovering Work Practice and Informing System Design, P. Luff, J. Hindmarsh and C. Heath (eds.), 150-166. Cambridge: Cambridge University Press.

Fairclough, N. (1992). Discourse and Social Change. Cambridge: Polity Press.

Firth, A. (1995). The Discourse of Negotiation: Studies of Language in the Workplace. Oxford: Pergamon.

Ford, J. D. (1999). Organizational change as shifting conversations. Journal of Organizational Change 12 (6): 490-500.

Ford, J. and Ford, L. W. (1995). The role of conversations in producing international change in organizations. Academy of Management Review 20 (3): 541-570.

- (2003). Conversations and the authoring of change. In Management and Language, D. Holman and R. Thorpe (eds.), 141-156. London: Sage.

Foucault, M. (1972a). The Archeology of Knowledge. New York: Pantheon.

- (1972b). The discourse on language. In The Archeology of Knowledge, M. Foucault (ed.), 215-238. London: Tavistock Publications.

Fox, S. (2000). Communities of practice, Foucault and actor-network theory. Journal of Management Studies 37 (6): 853-867.

Gabriel, Y. (1995). The unmanaged organization: Stories, fantasies and subjectivity. Organization Studies 16 (3): 477-479.

- (1998). Same old story or changing stories? Folkloric, modern and post-modern mutations. In Discourse and Organization, D. Grant, T. Keenoy, and C. Oswick (eds.), 84103. London: Sage.

—(1999). Organizations in Depth: The Psychoanalysis of Organizations. London: Sage.

- (2000). Story-Telling in Organizations. Oxford: Oxford University Press.

Gagliardi, P. (1990). Artifacts as pathways and remains of organizational life. In Symbols and Artifacts: Views of the Corporate Landscape, P. Gagliardi (ed.), 3-38. Berlin: Walter de Gruyter.

Gee, J. (1992). The Social Mind: Language, Ideology and Social Practice. New York: Bergin and Garvey. 
Gergen, K. (2000). Invitation to Social Construction. Thousand Oaks: Sage.

- (2001). Social Construction in Context. Thousand Oaks: Sage.

Grant, D. (1999). HRM, rhetoric and the psychological contract: A case of 'easier said than done'. International Journal of Human Resource Management 10 (2): 327-350.

Grant, D., Hardy, C., Oswick, C., and Putnam, L. (2004). The Handbook of Organizational Discourse. London: Sage.

Grant, D., Keenoy, T., and Oswick, C. (1998). Discourse and Organization. London: Sage.

- (2001). Organizational discourse: Key contributions and challenges. International Studies of Management and Organization 31 (3): 5-24.

Grimshaw, A. and Burke, P. J. (1995). What's Going on Here? Complementary Studies of Professional Talk. Norwood, NJ: Ablex.

Gumbrecht, H. U. and Pfeiffer, K. L. (1994). Materialities of Communication. Stanford, CA: Stanford University Press.

Gunnarson, B. L., Linell, P., and Nordberg, B. (1997). The Construction of Professional Discourse. London: Longman.

Hamilton, P. (1997). Rhetorical discourse of local pay. Organization 4 (2): 147-157.

Hardy, C., Lawrence, T., and Grant, D. (2005). Discourse and collaboration: The role of conversations and collective identity. Academy of Management Review 30 (1): 120.

Hardy, C., Lawrence, T., and Phillips, N. (1998a). Talk and action: Conversations and narrative in interorganizational collaboration. In Discourse and Organization, D. Grant, T. Keenoy, and C. Oswick (eds.), 65-83. London: Sage.

Hardy, C., Palmer, I., and Phillips, N. (2000). Discourse as a strategic resource. Human Relations 53 (9): 1227-1248.

Hardy, C., Phillips, N., and Lawrence, T. (1998b). Talking action: Conversations, narrative and action in interorganizational collaboration. In Discourse and Organization, D. Grant, T. Keenoy, and C. Oswick (eds.), 65-83. London: Sage.

- (2003). Resources, knowledge and influence. The effects of inter-organizational collaboration. Journal of Management Studies 40 (2): 289-315.

Harris, Z. (1963). Discourse Analysis Reprints-Papers on Formal Linguistics. The Hague: Mouton.

Harvey, D. (1996). Justice, Nature and the Geography of Difference. Oxford: Blackwell.

Hazen, M. A. (1993). Towards polyphonic organization. Journal of Organizational Change Management 6 (5): 15-26.

Heracleous, L. and Barrett, M. (2001). Organizational change as discourse: Communicative actions and deep structures in the context of information technology implementation. Academy of Management Review 44 (4): 755-778.

Heracleous, L. and Hendry, J. (2000). Discourse and the study of organization: Towards a structurational perspective. Human Relations 53 (10): 1251-1286.

Hjelmslev, L. (1961). Prolegomena to a Theory of Language. Madison, WI: University of Wisconsin Press.

Iedema, R. (2001). Resemiotization. Semiotica 135 (1/4): 23-40.

-(2003). Discourses of Post-Bureaucratic Organization. Amsterdam/Philadelphia: John Benjamins.

Iedema, R., Degeling, P., Braithwaite, J., and White, L. (2004a). 'It's an interesting conversation I'm hearing': The doctor as manager. Organization Studies 25 (1): 15-34.

Iedema, R., Sorensen, R., Braithwaite, J., Flabouris, A., and Turnbull, E. (2005). The teleoaffective limits of end-of-life care in the intensive care unit. Social Science \& Medicine 60 (4): $845-857$. 
Iedema, R., Sorensen, R., Braithwaite, J., and Turnbull, E. (2004b). Speaking about dying in the intensive care unit, and its implications for multi-disciplinary end-of-life care. Communication and Medicine 1 (1): 85-96.

Iedema, R. and Wodak, R. (1999). Organisational discourses and practices. Discourse and Society 10 (1): 5-20.

Jablin, F. M. and Putnam, L. (2001). The New Handbook of Organizational Communication: Advances in Theory, Research and Methods. Thousand Oaks: Sage.

Keenoy, T., Oswick, C., and Grant, D. (1997a). Organizational discourses: Text and context. Organization 4 (2): 147-157.

- (1997b). Themed section: Discourse and organization. Organization 4 (2): 511-544.

- (2000a). The discourse of organizing. Journal of Applied Behavioral Science 36 (2): 133-135.

- (2000b). Discourse, epistemology and organizations: A discursive footnote. Organization 7 (3): $542-544$.

Knights, D. and Morgan, G. (1991). Strategic discourse and subjectivity: Towards a critical analysis of corporate strategy in organizations. Organization Studies 12 (2): 251-273.

Knights, D. and Willmott, H. (1989). Power and subjectivity at work: From degradation to subjugation in social relations. Sociology 23 (4): 535-558.

Kress, G. and van Leeuwen, T. (1996). Reading Images: The Grammar of Visual Design. London: Routledge.

- (2001). Multimodality. London: Sage.

Latour, B. (1986). Visualization and cognition: Thinking with eyes and hands. Knowledge and Society: Studies in the Sociology of Culture Past and Present 6: 1-40.

- (1988). The Pasteurization of France. Cambridge, MA: Harvard University Press.

- (1990). The force and the reason of experiment. In Experimental Inquiries, H. E. LeGrand (ed.), 49-80. Netherlands: Kluwer Academic Publishers.

- (1992). Where are the missing masses? The sociology of a few mundane artifacts. In Shaping Technology/Building Society: Studies in Socio-technical Change, W. E. Bijker and J. Law (eds.), 225-258. Cambridge, MA: The MIT Press.

Lave, J. and Wenger, E. (1990). Situated Learning: Legitimate Peripheral Participation. Cambridge: Cambridge University Press.

Law, J. (1994). Organising Modernity. Oxford: Blackwell.

- (1999). After ANT: Complexity, naming and topology. In Actor Network Theory and After, J. Law and J. Hassard (eds.), 1-14. Oxford: Blackwell Publishers.

Law, J. and Bijker, W. E. (1992). Post-script: Technology, stability and social theory. In Shaping Technology/Building Society, W. E. Bijker and J. Law (eds.), 290-308. Cambridge, MA: The MIT Press.

Lawrence, T., Hardy, C., and Phillips, N. (2002). Institutional effects of inter-organizational collaboration: The case of mère et enfant. Academy of Management Journal 45 (1): 281-290.

Lawrence, T., Phillips, N., and Hardy, C. (1999). Watching whale-watching: Exploring the discursive foundations of collaborative relationships. Journal of Applied Behavioral Science 35 (4): 479-502.

Lemke, J. (1995). Textual Politics: Discourse and Social Dynamics. London: Taylor \& Francis.

Linell, P. and Sarangi, S. (1998). Discourse across professional boundaries. Text 18 (2): $143-$ 318.

Maguire, S. (2004). The co-evolution of technology and discourse: A study of substitution processes for the insecticide DDT. Organization Studies 25 (1): 113-134.

Maguire, S., Phillips, N., and Hardy, C. (2001). When 'silence = death', keep talking: Trust, control and the discursive construction of identity. Organization Studies 22 (2): 287-312.

Mangham, I. (1998). Emotional discourse in organizations. In Discourse and Organization, D. Grant, T. Keenoy, and C. Oswick (eds.), 51-64. London: Sage. 
Marshak, R. (1998). A discourse on discourse: Redeeming the meaning of talk. In Discourse and Organization, D. Grant, T. Keenoy and C. Oswick (eds.), 15-30. London: Sage.

Martin, J. (2002). Organizational Culture: Mapping the Terrain. London: Sage.

Martin, J. R. (1992). English Text: System and Structure. Amsterdam: Benjamins.

Mauws, M. (2000). But it is art? Decision making and discursive resources in the field of cultural reproduction. Journal of Applied Behavioral Science 36 (2): 229-244.

Mumby, D. (1998). Power, politics and organizational communications: Theoretical perspectives. In The New Handbook of Organizational Communication, F. M. Jablin and L. Putnam (eds.), 106-134. London: Sage.

Mumby, D. and Clair, R. D. (1997). Organizational discourse. In Discourse as Social Interaction: Discourse Studies Volume 2-A Multidisciplinary Introduction, T. van Dijk (ed.), 181-205. Newbury Park, CA: Sage.

Mumby, D. and Stohl, C. (1991). Power and discourse in organization studies: Absence and the dialectic of control. Discourse \& Society 2 (3): 313-332.

Orlikowski, W. J. and Yates, J. A. (1994). Genre repertoire: The structuring of communicative practices in organizations. Administrative Science Quarterly 39 (4): 541-574.

Orlikowski, W. J., Yates, J. A., and Okamura, K. (1999). Explicit and implicit structuring of genres: Electronic communication in a Japanese R\&D organization. Organization Science 10 (1): 83-103.

Oswick, C., Keenoy, T., and Grant, D. (1997). Managerial discourses: Words speak louder than actions? Journal of Applied Management Studies 6 (1): 5-12.

- (2000a). Discourse, organizations and organizing: Concepts, objects, subjects. Human Relations 53 (9): 1115-1123.

- (2000b). Discourse, organization and epistemology. Organization 7 (3): 511-512.

Oswick, C. and Montgomery, J. (1999). Images of an organisation: The use of metaphor in a multinational company. Journal of Organisational Change Management 21 (5): 501-523.

Pettigrew, A. (1979). On studying organisational cultures. Administrative Science Quarterly 24 (4): 570-581.

Phillips, N. (1995). Telling organizational tales: On the role of narrative fiction in the study of organizations. Organization Studies 16 (4): 625-644.

Phillips, N. and Hardy, C. (1997). Managing multiple identities: Discourse legitimacy and the resources in the UK refugee system. Organization 4 (2): 159-185.

-(2002). Discourse Analysis: Investigating Processes of Social Construction. London: Sage.

Phillips, N., Lawrence, T., and Hardy, C. (2000). Inter-organizational collaboration and the dynamics of institutional fields. Journal of Management Studies 37 (2): 23-43.

Putnam, L. and Fairhurst, G. (2001). Discourse analysis in organizations: Issues and concerns. In The New Handbook of Organizational Communication: Advances in Theory, Research and Methods, F. M. Jablin and L. Putnam (eds.), 235-268. Newbury Park, CA: Sage.

Putnam, L. L. and Pacanowsky, M. E. (1983). Communication and Organization: An Interpretive Approach. Beverly Hills, CA: Sage.

Putnam, L. and Roloff, M. (1992). Communication and Negotiation. Newbury Park, CA: Sage.

Raisanen, C. and Linde, A. (2004). Technologizing discourse to standardize projects in multi-project organizations: Hegemony by consensus? Organization 11 (1): 101-121.

Reddy, M. (1979). The conduit metaphor - a case of frame conflict in our language about language. In Metaphor and Thought, A. Ortony (ed.), 284-324. Cambridge: Cambridge University Press.

Reed, M. (1997). In praise of duality and dualism: Rethinking agency and structure in organizational analysis. Organization Studies 18 (1): 21-42. 
- (1998). Organizational analysis as discourse analysis: A critique. In Discourse and Organization, D. Grant, T. Keenoy, and C. Oswick (eds.), 193-213. London: Sage.

- (2000). The limits of discourse analysis in organizational analysis. Organization 7 (3): 524-530.

Rhodes, C. (2001). Writing Organization. Amsterdam/Philadelphia: John Benjamins.

- (2002). Text, plurality and organizational knowledge. Ephemera 2 (2): 98-118.

Robb, P. (1998). Midnight in Sicily. London: The Harvill Press.

Roberts, C. and Sarangi, S. (1999). Hybridity in gatekeeping discourse: Issues of practical relevance for the researcher. In Talk, Work and Institutional Order: Discourse in Medical, Mediation and Management Settings, S. Sarangi and C. Roberts (eds.), 473-503. Berlin/ New York: Mouton de Gruyter.

Salzer-Morling, M. (1998). As God created earth ... A saga that makes sense? In Discourse and Organization, D. Grant, T. Keenoy, and C. Oswick (eds.), 104-118. London: Sage.

Sarangi, S. and Roberts, C. (1999a). Talk, Work and the Institutional Order: Discourse in Medical, Mediation and Management Settings. Berlin/New York: Mouton de Gruyter.

- (1999b). Introduction: The dynamics of interactional and institutional orders in workrelated settings. In Talk, Work and the Institutional Order: Discourse in Medical, Mediation and Management Settings, S. Sarangi and C. Roberts (eds.), 1-57. Berlin/New York: Mouton de Gruyter.

Sarangi, S. and Slembrouck, S. (1996). Language, Bureaucracy and Social Control. London: Longman.

Schatzki, T. (2002). The Site of the Social. University Park, PA: The Pennsylvania State University Press.

Schein, E. H. (1983). The role of the founder in creating organizational culture. Organizational Dynamics Summer: 13-28.

- (1984). Coming to a new awareness of organizational culture. Sloan Management Review Winter: 3-16.

Schiffrin, D., Tannen, D., and Hamilton, H. (2003). The Handbook of Discourse Analysis. Oxford: Blackwell.

Shaw, P. (2002). Changing Conversation in Organizations: A Complexity Approach to Change. London/New York: Routledge.

Shotter, J. (1991). The rhetorical-responsive nature of mind: A social constructionist account. In Against Cognitivism: Alternative Foundations for Cognitive Psychology, A. Still and A. Costall (eds.), 55-80. Hemel Hempstead: Harvester Wheatsheaf.

Shotter, J. and Cunliffe, A. (2003). Managers as practical authors: Everyday conversations for action. In Management and Language: The Manager as Practical Author, D. Holman and R. Thorpe (eds.), 15-37. London: Sage.

Shotter, J. and Gergen, K. (1989). Texts of Identity. Newbury Park, CA: Sage.

Silverman, D. (1970). The Theory of Organizations. London: Heinemann.

Still, A. and Costall, A. (1991). Against Cognitivism: Alternative Foundations for Cognitive Psychology. Hemel Hampstead: Harvester Wheatsheaf.

Taylor, J. R. and Van Every, E. J. (2000). The Emergent Organization: Communication as its Site and Interface. $\mathrm{NJ} /$ London: Lawrence Erlbaum Associates.

Thibault, P. (1991). Social Semiotics as Praxis: Text, Social Meaning Making, and Nabokov's Ada. Minneapolis, MN: University of Minnesota Press.

Torfing, J. (1999). New Theories of Discourse: Laclau, Mouffe and Zizek. Oxford: Blackwell.

Turner, B. (1993). The rise of organizational symbolism. In The Theory and Philosophy of Organizations: Critical Issues and New Perspectives, J. Hassard and D. Pym (eds.), 8396. London: Routledge. 
van Dijk, T. (1997a). Discourse as Social Interaction: Discourse Studies Volume 2-A Multidisciplinary Introduction. Newbury Park, CA: Sage.

- (1997b). The study of discourse. In Discourse as Structure and Process, T. van Dijk (ed.), 1-34. London: Sage.

- (1997c). Discourse as Structure and Process. London: Sage.

Verschueren, J., Östman, J., Blommaert, J., and Bulcaen, C. (2003). Handbook of Pragmatics. Amsterdam: John Benjamins.

Weick, K. and Roberts, K. H. (1993). Collective mind in organizations: Heedful interrelating on flight decks. Administrative Science Quarterly 38: 357-381.

Wenger, E. (1998). Communities of Practice. Cambridge: Cambridge University Press.

Wodak, R. (1996). Disorders of Discourse. London: Longman.

Woodilla, J. (1998). Workplace conversations: The text of organizing. In Discourse and Organization, D. Grant, T. Keenoy, and C. Oswick (eds.), 31-50. London: Sage.

David Grant is Professor of Organizational Studies, The School of Business, The University of Sydney. His primary area of research interest is organizational discourse, especially where it relates to organizational change initiatives. He has published in a range of management and organization journals and has coedited Discourse and Organization (1998, with Tom Keenoy and Cliff Oswick) and the Handbook of Organizational Discourse (2004, with Cynthia Hardy, Cliff Oswick, and Linda Putnam). Address for correspondence: Work and Organizational Studies (Rm. 511), The School of Business, The New Economics and Business Building (H 69), The University of Sydney, NSW 2006, Australia〈d.grant@econ. usyd.edu.au $\rangle$.

Rick Iedema is Senior Lecturer at the School of Public Health and Community Medicine, The University of New South Wales. He researches the organization and enactment of health care provision, and he has published in the areas of discourse analysis, organization theory, and health services research. His book, Discourses of Post-Bureaucratic Organization, was published in 2003. He is Chief Investigator on two Australian Research Council projects investigating the organization of local health care services. Address for correspondence: Centre for Clinical Governance Research, School of Public Health and Community Medicine, The University of New South Wales, NSW 2052, Australia〈r.iedema@unsw. edu.au $\rangle$. 